\title{
PET-CT Beyond FDG: A Quick Guide to Image Interpretation
}

S. Fanti, M. Farsad, and L. Mansi, eds.

Berlin, Germany: Springer-Verlag, 2010, 243 pages, $\$ 79.95$

This book is a companion to the editors' recently published book, Atlas of PET-CT: A Quick Guide to Image Interpretation, which focuses exclusively on the use of ${ }^{18} \mathrm{~F}$-FDG. When PET/CT is used, the CT information remains the same and the PET component can give various diagnostic contributions, depending on the radiotracer used. Although ${ }^{18} \mathrm{~F}-\mathrm{FDG}$ generally is an excellent cancer imaging agent and will be the workhorse of clinical PET for many years, there are some settings in which other radiopharmaceuticals offer advantages. Other agents are now gaining widespread acceptance not only in research but also in clinical practice, with the acquisition of promising results in the management of various cancers.

This book was made possible by the joint effort of the entire nuclear medicine and radiopharmacy scientific community, which, in the last 30 years, has pursued research in the field of molecular imaging. Pioneers with a scientific background not only in imaging but also in radiochemistry, physiology, pharmacology, molecular biology, and clinical medicine have been deeply involved in this research. To better define the role of non- ${ }^{18} \mathrm{~F}$-FDG agents, the industry has to invest in the production and distribution of new radiotracers. Nuclear physicians have to optimize the use of these agents and the associated instrumentation and also understand the real relevance of these procedures in clinical practice.

This book, designed to serve as a reference for both nuclear physicians and radiologists and for trainees in nuclear medicine and radiology, covers a wide range of new tracers such as ${ }^{18} \mathrm{~F}$ - and ${ }^{11} \mathrm{C}$-choline, ${ }^{11} \mathrm{C}$-methionine, ${ }^{18} \mathrm{~F}$ -
ethyl-L-tyrosine, ${ }^{68} \mathrm{Ga}$-DOTANOC, ${ }^{11} \mathrm{C}$-acetate, ${ }^{11} \mathrm{C}$-thymidine, and ${ }^{18} \mathrm{~F}$-DOPA. The objective was to contribute the best efforts in the stimulating area of clinical development in nuclear medicine, with an emphasis on image interpretation by recognition of normal, benign, and malignant lesions and clear instructions on learning points and pitfalls.

There are 15 chapters, including a final chapter of current references. Chapter 1 deals with the importance of radiotracers other than ${ }^{18} \mathrm{~F}-\mathrm{FDG}$ in oncology, and chapter 2 considers PET isotopes. Chapters 3 through 14 demonstrate examples of imaging with non- ${ }^{18} \mathrm{~F}-\mathrm{FDG}$ agents, including 25 with choline, 10 with methionine, 7 with fluoride, 11 with tyrosine, 17 with somatostatin receptor, 16 with acetate, 11 with thymidine, 11 with dopa, 9 with hypoxia factor, 11 with angiogenesis factor, 4 with hormone receptor, and 4 with tryptophan. About 500 images are included; they are clear and of high quality and have arrows pointing out abnormal findings. There is a teaching point for each agent. The subject index is useful.

I highly recommend this book-a user-friendly guide to PET/CT beyond ${ }^{18} \mathrm{~F}-\mathrm{FDG}$ - to nuclear physicians, radiologists, and researchers in oncology as well as to trainees in the imaging field.

E. Edmund Kim

M.D. Anderson Cancer Center

1515 Holcombe Blvd., Unit 1264

Houston, TX 77030

E-mail:ekim@di.mdacc.tmc.edu 